\title{
ICONOGRAFÍA ANIMAL EN LAS ARTESANÍAS DEL MERCADO ARTESANAL "LA MARISCAL" DE QUITO-ECUADOR
}

\author{
Animal iconography in the craftsmanship of the "La Mariscal"' craft market of Quito- \\ Ecuador
}

Ana Belén MANZANILLAS ${ }^{1 *}$, Alexander Patricio GUALOTUÑA ${ }^{1}$, María José PICO$^{1}$

${ }^{1}$ Universidad Central del Ecuador, Facultad de Ciencias Biológicas, Carrera de Ciencias Biológicas y Ambientales, Quito, Ecuador *abmanzanillas@uce.edu.ec

Submitted: 27/08/2020; Accepted: 15/10/2020; Published: 10/01/2021

\section{RESUMEN}

El pueblo Otavaleño por décadas ha expresado su cultura a través de representaciones faunísticas en la decoración de las artesanías, las mismas que tienen un valor ancestral, histórico, tradicional y de conservación del patrimonio natural. Sin embargo, en la actualidad su connotación cultural ha cambiado por la transculturación occidental. Por ello, el presente estudio tiene como objetivo caracterizar la iconografía animal representadas en las artesanías que elaboran y comercializan en el Mercado artesanal "La Mariscal" de Quito. Se realizaron observaciones y entrevistas semi-abiertas dirigidas a los comerciantes del mercado. Los resultados obtenidos indican que los artesanos otavaleños consideran a las llamas, cuyes, conejos y cóndor andino como especies representativas de su cosmovisión andina. Si bien, los artesanos conocen el valor cultural de sus propias artesanías, el $80 \%$ de los comerciantes lo ignoran. Esto hace que las artesanías pierdan su autenticidad y su sentido de pertenencia a una comunidad, evitando que su cultura trascienda fronteras.

PALABRAS CLAVE: Adornos, Comerciantes, Cultura, Etnozoología, Simbología.

\begin{abstract}
The Otavaleño people for decades have expressed their culture through fauna representations in the decoration of handicrafts, which have an ancestral, historical, traditional, and conservation value of the natural heritage. However, today its cultural connotation has changed due to Western transculturation. For this reason, the present study aims to characterize the animal iconography represented in the handicrafts made and sold in the "La Mariscal" craft market in Quito. Observations and semi-open interviews were conducted with market traders. The results obtained indicate that Otavaleño artisans consider llamas, guinea pigs, rabbits, and Andean condors as representative species of their Andean worldview. Although artisans know the cultural value of their own crafts, $80 \%$ of merchants ignore it. This makes the crafts lose their authenticity and their sense of belonging to a community, preventing their culture from transcending borders.
\end{abstract}

KEYWORDS: Ornaments, Merchants, Culture, Ethnozoology, Symbolism.

\section{INTRODUCCIÓN}

A lo largo de la historia los diferentes grupos multiétnicos ecuatorianos caracterizaron sus artesanías con representaciones faunísticas adecuándose a los estilos y a las temáticas 
reinantes en su momento y, con ello, conservaban sus tradiciones (GUAPISACA, 2019). El Instituto Nacional de Patrimonio Cultural (ECUADOR, 2014), analizó animales en esculturas y pinturas de tres culturas que regían en la provincia de Tungurahua, enunciando que las representaciones zoológicas deben tener una interpretación simbólica desde una perspectiva naturalista. Sin embargo, Larraín (1980) expone que las culturas imbabureñas representaban animales macroscópicos de acuerdo con características, funciones y el manejo de los recursos del sector agrícola.

La etnozoología, que estudia las interacciones humanos-animales, incluye el conocimiento zoológico tradicional que está asociado de manera inseparable con prácticas y creencias de los grupos humanos (indígenas, campesinos, pescadores artesanales, entre otros), comúnmente llamadas poblaciones tradicionales. En este sentido, se caracteriza como siendo de gran importancia en la conservación de especies y en las políticas públicas ambientales, a fin de garantizar una gestión compartida de los recursos faunísticos con aplicabilidad de estrategias viables a escalas locales, regionales y globales (ARGUETA et al., 2012; FERRO, 2015).

Para la gran mayoría de los artesanos la elaboración de artesanías tiene un significado muy particular, ya que es un vínculo entre la familia y lo que la naturaleza les ofrece. Son actividades que se desarrollan en base a su principio fundamental y la transmisión del conocimiento favorece la conservación del patrimonio natural, cultural y ambiental (GUAPISACA, 2019).

De ahí, la importancia de este estudio debido a que recopila valiosa información acerca de las artesanías que representan la cosmovisión de la cultura ancestral. Los artesanos a través de las figuras plasman en diferentes formas, figuras o símbolos su historia, su diario vivir, festividades, sitios sagrados, sus deidades de culto, animales, entre otros (VALDÉS et al., 2001).

El objetivo del presente estudio es caracterizar las percepciones de los artesanos sobre la iconografía animal representadas en las artesanías que elaboran y comercializan en el Mercado artesanal "La Mariscal” de Quito.

\section{MATERIALES Y MÉTODOS}

\section{1 Área de estudio}

El Mercado artesanal "La Mariscal” fue inaugurado el 12 de mayo del 2000, su construcción se debió a la presión de los artesanos que vendían sus productos en la avenida 
Amazonas y calles aledañas del sector de La Mariscal. Actualmente, el Mercado artesanal se encuentra ubicado en el centro-norte de la ciudad de Quito-Ecuador, en el sector denominado "La Mariscal", por las calles Reina Victoria y Juan León Mera (0¹2’10.03’' S y 78²9’33.00’' O) (Figura 1). Actualmente, es uno de los mercados nacionales más reconocidos por la venta de artesanías ecuatorianas con sus aproximadamente 200 locales que lo conforman, donde se puede encontrar una infinidad de productos como: artesanías, instrumentos musicales, ropa, tejidos, bordados, joyas, dulces, licores tradicionales, entre otros. La mayoría de dichos productos son elaborados a mano aplicando técnicas indígenas ancestrales, por lo que tienen una alta demanda ya que diariamente visitan el mercado 1500 turistas y en época de agosto-septiembre más de 2000 visitantes, según el Ministerio del Turismo (ECUADOR, 2017).

Dicho mercado alberga alrededor de 187 trabajadores autónomos de diferentes localidades y de pueblos originarios del Ecuador, algunos son artesanos y otros son comerciantes intermediarios del producto artesanal (ECUADOR, 2017). La mayoría de personas que laboran en el lugar se autoidentifican como indígenas otavaleños, cuya principal actividad económica es la venta de artesanías originarias de su pueblo o, en algunos casos, exportadas de otros lugares. En este mercado, la venta de artesanías es un negocio familiar, por ello lo realizan hombres y mujeres, tanto jóvenes como longevas.

Al ser una zona netamente urbana, la variedad de especies tanto de flora como de fauna es escasa. Sin embargo, se puede observar algunas aves que se han adaptado a condiciones urbanas como: Eriocnemis nigrivestis (Bourcier \& Mulsant, 1852) zamarrito pechinegro; Zonotrichia capensis (Statius Müller, 1776) gorrión; Turdus fuscater (Lafresnaye \& D'Orbigny, 1837) mirlo y Zenaida auriculata (Des Murs, 1847) palomas. La zona se caracteriza por la alta densidad poblacional y por estar rodeada principalmente por grandes edificaciones, lo que explica la ausencia de animales silvestres (SARANGO, 2013). 


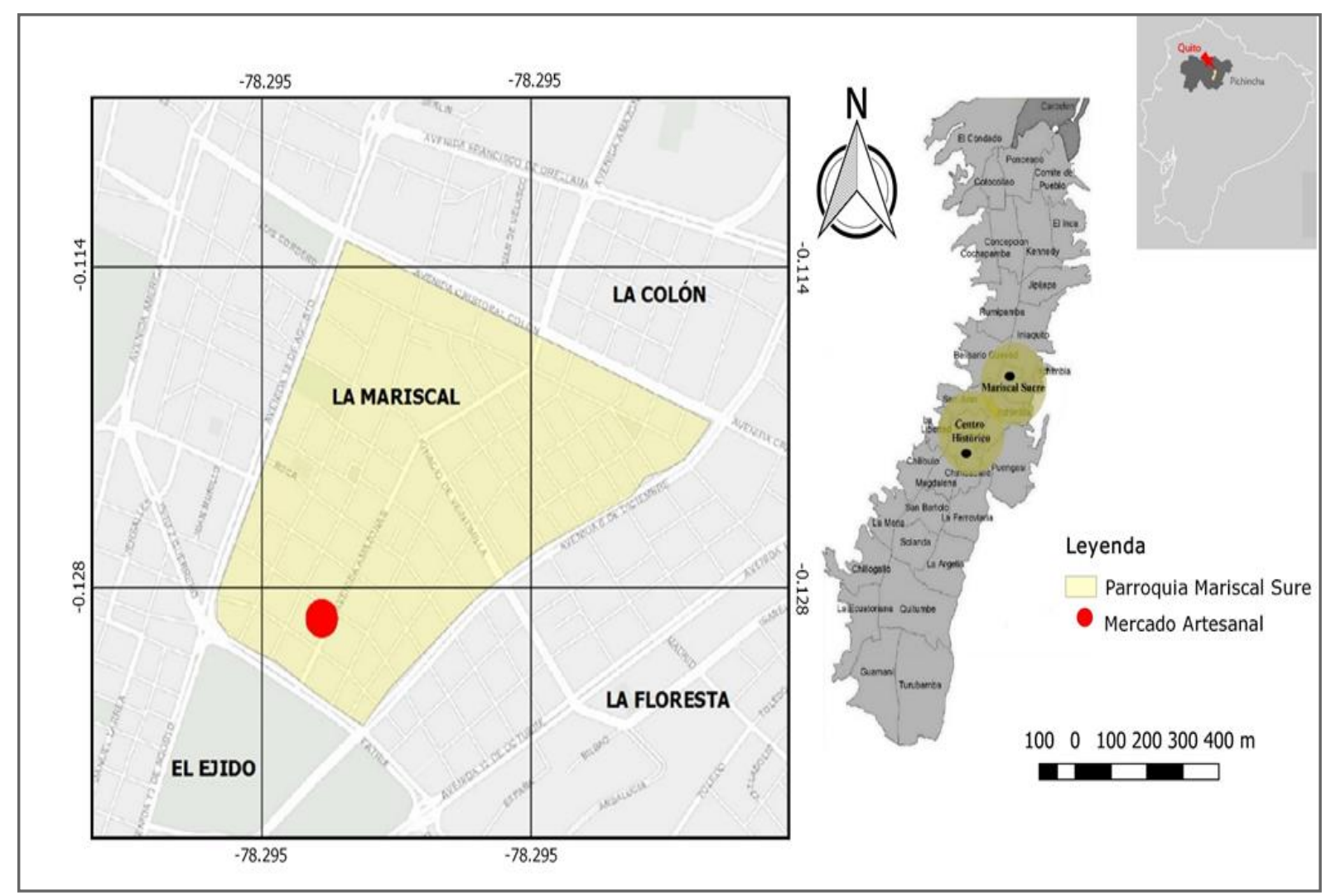

Figura 1: Localización geográfica del Mercado Artesanal La Mariscal en la ciudad de Quito. Fuente: adaptado de López (2009).

\subsection{Metodología}

Esta investigación es exploratoria, descriptiva y cualitativa. Se empleó la técnica observacional, la cual nos permitió conocer de manera más objetiva las características generales del Mercado, los productos que se ofrecen, el movimiento turístico y más. Además, se realizaron entrevistas semi-abiertas a treinta informantes clave, entre los cuales se encontraban los artesanos, así como comerciantes de los distintos locales del Mercado (Figura 2). Para ello, se proporcionó información a los artesanos acerca de la temática del estudio, dando a conocer los objetivos de esta investigación, su participación en la misma con los riesgos, beneficios y, sobre todo, el derecho a retirar su participación de forma voluntaria durante el proceso de la entrevista. Es así, que se llegó a un acuerdo verbal donde los entrevistados nos proporcionarían información con la condición de mantener en anonimato las entrevistas y no realizar fotografías de los artesanos y comerciantes. De esta manera, los entrevistados tuvieron la plena confianza de proporcionar información sabiendo que el fin de la investigación es enriquecer el conocimiento educativo así como social. 


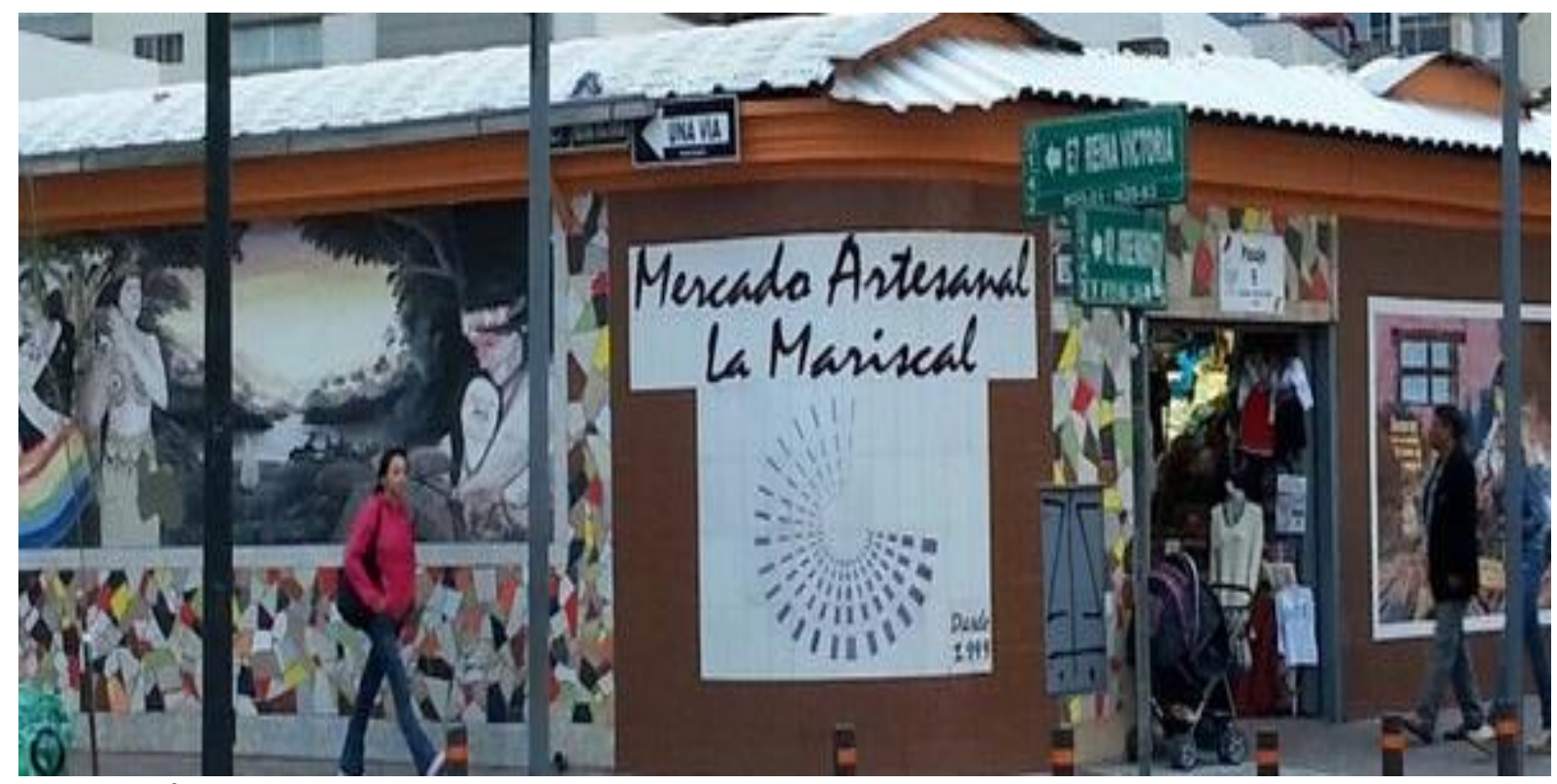

Figura 2: Área de investigación Mercado Artesanal “La Mariscal”. Fuente: los autores (2019).

Las entrevistas semi-abiertas se llevaron a cabo el día 11 de mayo del 2019 (Figura 3). RIVERA-CRUZ et al. (2008), recomiendan conocer la identidad cultural y de género del grupo que realizan las piezas para conocer el verdadero valor intrínseco de las artesanías. Por ello, la entrevista se dividió en dos partes: la primera trata sobre datos del entrevistado que incluyeron edad, género, ocupación e identidad, mientras la segunda son tres preguntas enfocadas sobre el tipo de artesanías, su valor cultural y otras referentes a su elaboración.

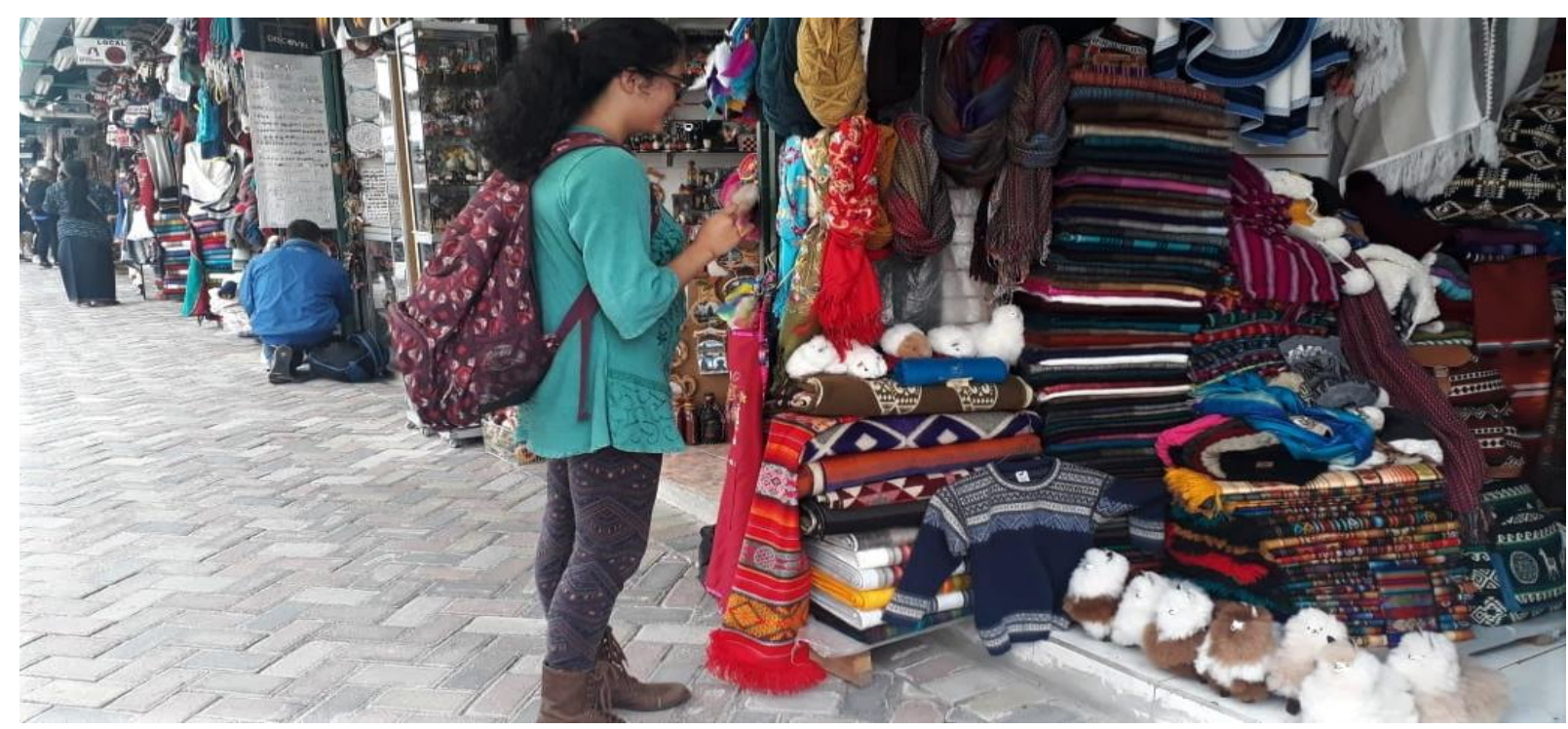

Figura 3: Entrevistas realizadas a los comerciantes. Fuente: los autores (2019).

Los datos obtenidos en las entrevistas fueron procesados en el programa informático Microsoft Excel® 2013, donde se aplicó estadística descriptiva y se obtuvo datos de la medida de tendencia central y porcentajes. Los mismos fueron representados en formato de 
gráficos de pastel para mostrar mejor la proporción en que aparecen las diferentes respuestas con respecto a cada pregunta sobre iconografía animal. Además, con la previa autorización de los comerciantes, toda la información recolectada fue fotografiada como evidencia para posteriormente confirmar la identificación taxonómica dada por los entrevistados.

\section{RESULTADOS Y DISCUSIÓN}

El $65 \%$ de los encuestados pertenecen a la cultura otavaleña, donde más de la mitad son mujeres las que se dedican a la venta de artesanías. Esto puede deberse a que las artesanías son consideradas como una actividad doméstica donde todos participan en esta tarea que genera (RIVERA-CRUZ et al, 2008). En la ciudad de Otavalo hay una gran diversidad de formas y materiales con las que fabrican artesanías (BUENAÑO et al., 2016). Las mismas son muy parecidas a las que se ofrecen en el Mercado Artesanal "La Mariscal". Si bien, ambos lugares están distantes entre sí, el grupo étnico al que pertenecen los artesanos es el mismo. Por lo que, las artesanías que elaboran son el resultado de la cosmovisión de su cultura otavaleña.

Las artesanías de tipo textil prevalecen en el mercado "La Mariscal", ya que son realizadas grandes cantidades de ponchos, bufandas y pantalones. Seguido, están las artesanías en base a madera, donde se aplican diferentes técnicas de tallado para crear piezas decorativas. Mientras que el cuero lo utilizan para fabricar carteras, cinturones, billeteras y más. Otros tipos de artesanía menos animal como: conchas, plumas y pezuñas (Figura 4). A título de comparación, los artesanos mexicanos emplean, en líneas generales, similares materiales como: lana, algodón, seda, barro, madera, metales, entre otros (RIVERA- CRUZ et al., 2008).

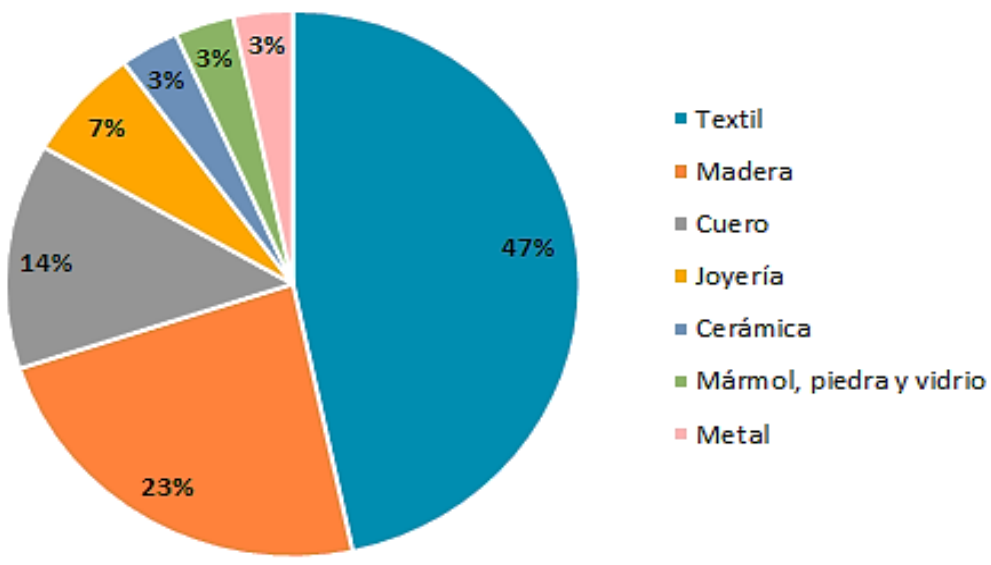

Figura 4: Comercialización de los distintos tipos de artesanías. Fuente: elaboración propia. 
En cuanto a la presencia de las representaciones faunísticas en la decoración de las artesanías, se identificaron animales vertebrados e invertebrados. Los mismos se dividieron en los siguientes grupos taxonómicos: mamíferos, aves, reptiles, anfibios e insectos (Figura $5)$.

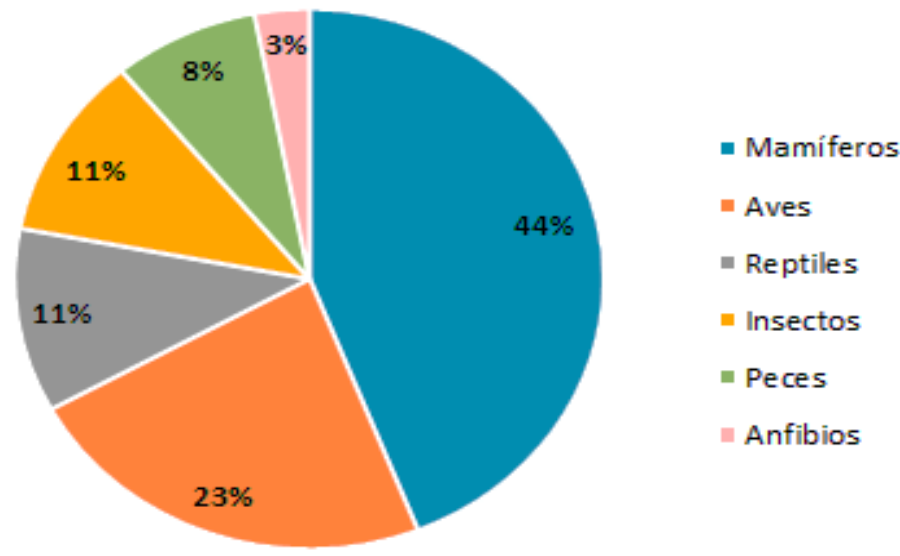

Figura 5: Representatividad faunística en la comercialización de artesanías. Fuente: elaboración propia.

El grupo de mamíferos fue el más representado en las piezas artesanales. Para su elaboración utilizaron diferentes materiales como las pezuñas de las vacas para revestir pequeños vasos, que antiguamente lo usaban para servir bebidas fermentadas en los rituales, según informó un artesano. Otro comerciante adulto mayor relató también sobre el empleo de las pezuñas de ovejas como chajchas (Figura 6). El cual, es un instrumento de persecución andina que tradicionalmente se elaboraba a base de pezuñas de llama y según el mismo comerciante son utilizados para ahuyentar malos espíritus (SARASTY, 2015).
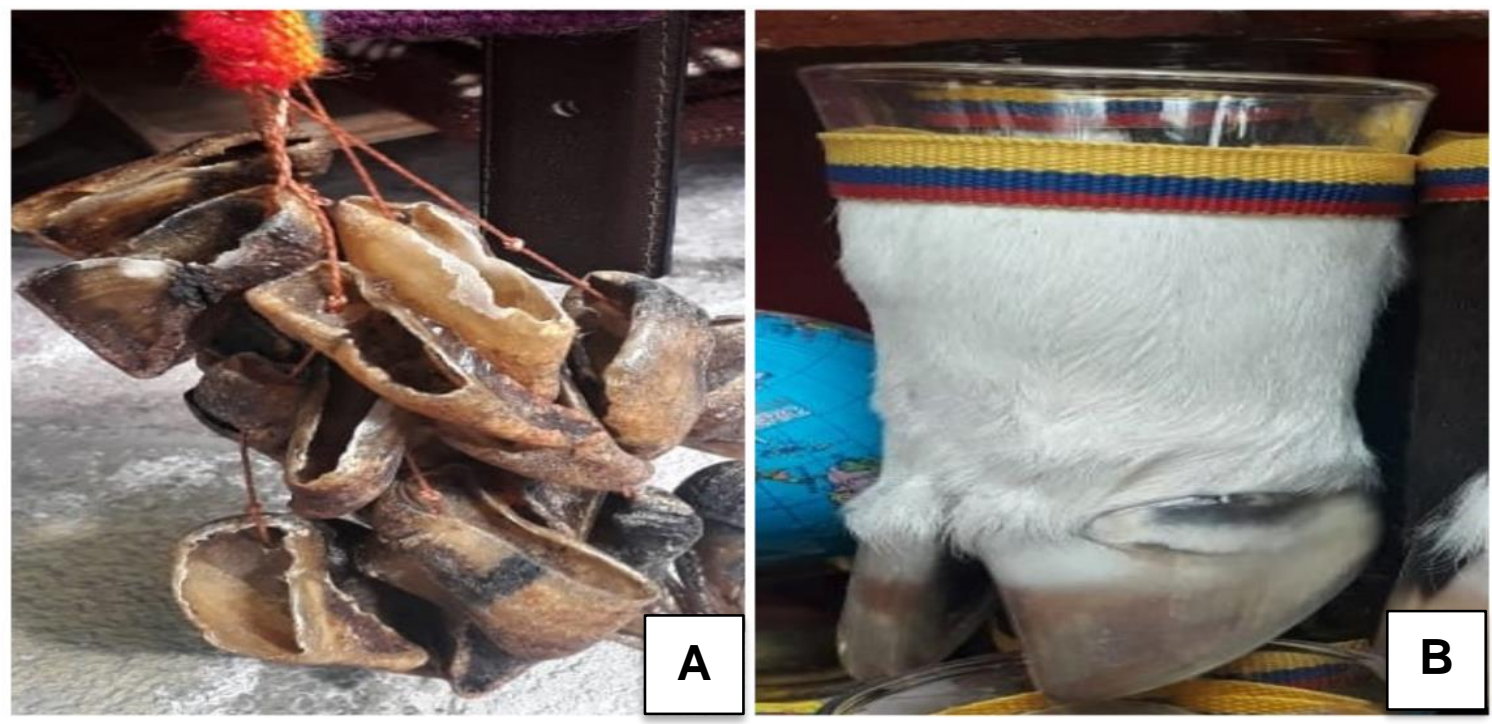
Figura 6: Artesanías en base a las pezuñas de algunos mamíferos artiodáctilos: A. pezuñas de ovejas, B. pezuña de vaca. Fuente: los autores (2019).

La mayoría de los artesanos y comerciantes aseguraron pertenecer a pueblos andinos, por lo que en sus artesanías representan muy a menudo a la fauna doméstica que vive en los Andes ecuatorianos., misma que tiene importancia alimenticia y textil dentro de sus comunidades. Son ellos: Sylvilagus andinus (Thomas, 1897) conejo de páramo; Cavia porcellus (Linnaeus, 1758) cuy; Ovis orientalis aries (Linnaeus, 1758) oveja y Lama glama (Linnaeus, 1758) llama, siendo estas últimas las más representadas en diferentes artesanías desde metal hasta textil (Figura 7).
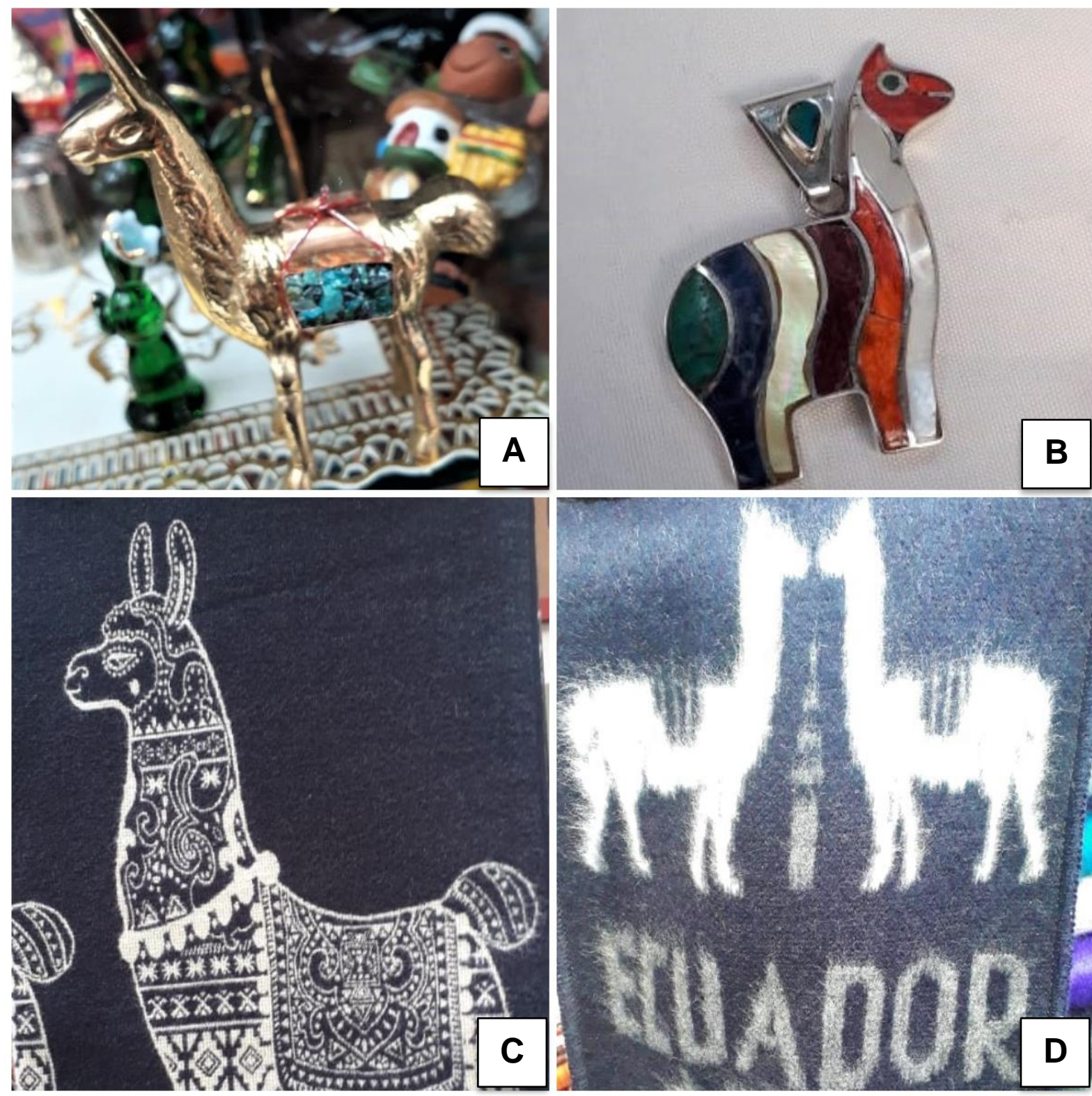

Figura 7: Llamas representadas en diferentes tipos de artesanías: A. Adorno de metal, B. Dije de plata, C. cobija y D. Poncho. Fuente: los autores (2019). 
Como se nota en la figura 8 , los conejos y cuyes en su mayoría son representados en peluches y para su elaboración emplean el pelo del propio animal. Además, elaboran llaveros con la cola del conejo, que según una comerciante informó, son usados como amuletos de la buena suerte y de protección, razón por la cual se los podía emplear como un llavero (Figura $8)$.
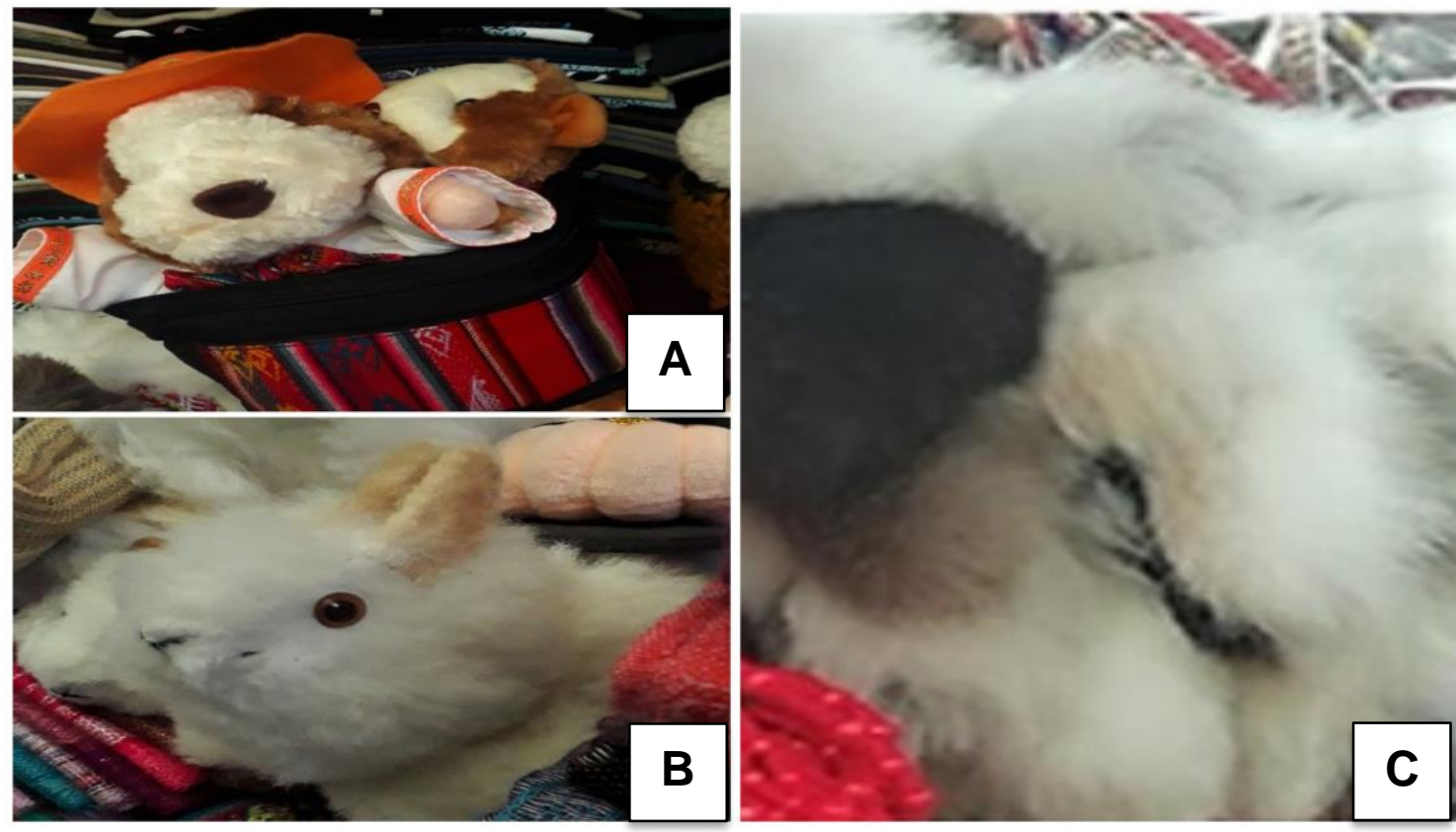

Figura 8: Peluches de: A. Cuy, B. Conejo, C. Llavero de cola de conejo. Fuente: los autores (2019).

Si bien, se presenció varias artesanías de fauna doméstica andina, son pocos los animales silvestres representados en las piezas artesanales. Dos especies andinas fueron las más frecuentes: Pseudalopex culpaeus (Molina, 1782) lobo de páramo y Odocoileus ustus (Trouessart, 1910) venado de cola blanca (Figura 9). 

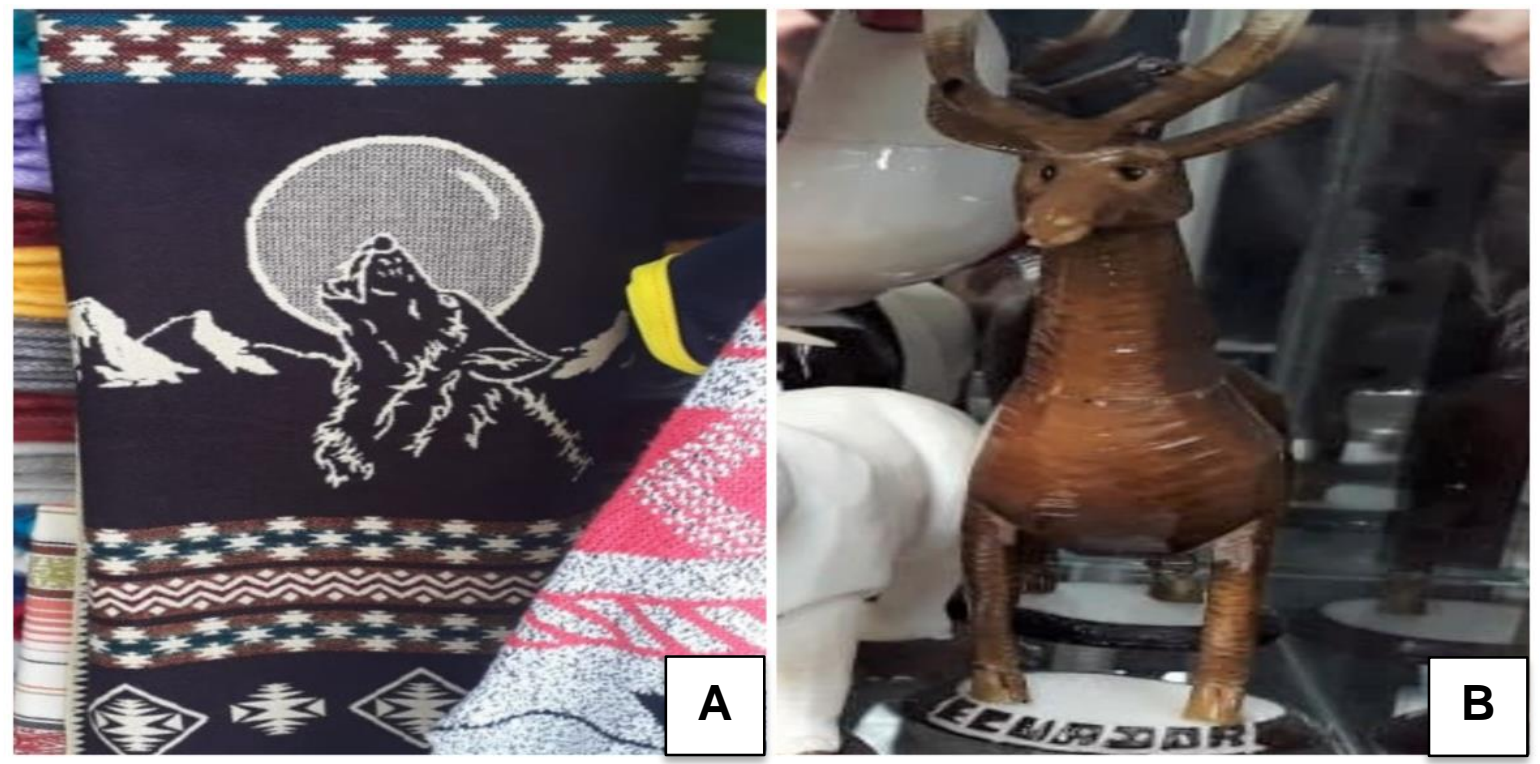

Figura 9: Artesanías de animales silvestres: A. textil bordado con imagen de un lobo, B. Adorno en forma de venado elaborado en tagua. Fuente: los autores (2019).

También se observó figuras de animales emblemáticos de otros países que no se encuentran distribuidos naturalmente en Ecuador como: búfalos, elefantes, rinocerontes, jirafas, cebras, osos pandas, entre otros (Figura 10). Estas artesanías con su iconografía animal representan otras culturas ajenas a la cosmovisión andina que cada vez más desplazan a las artesanías autóctonas del Ecuador. Esto se debe a que son animales más llamativos y conocidos por el turista extranjero según indicaron varios entrevistados. Así mismo, sucede con la materia prima utilizada para la elaboración de los textiles. Según explicó un artesano, antes elaboraban las cobijas con lana de oveja, pero ahora lo hacen en su mayoría con lana sintética. En su habla: "Nadie quiere pagar lo que en verdad cuesta estos productos por lo que nos vemos obligados a bajar la calidad". 

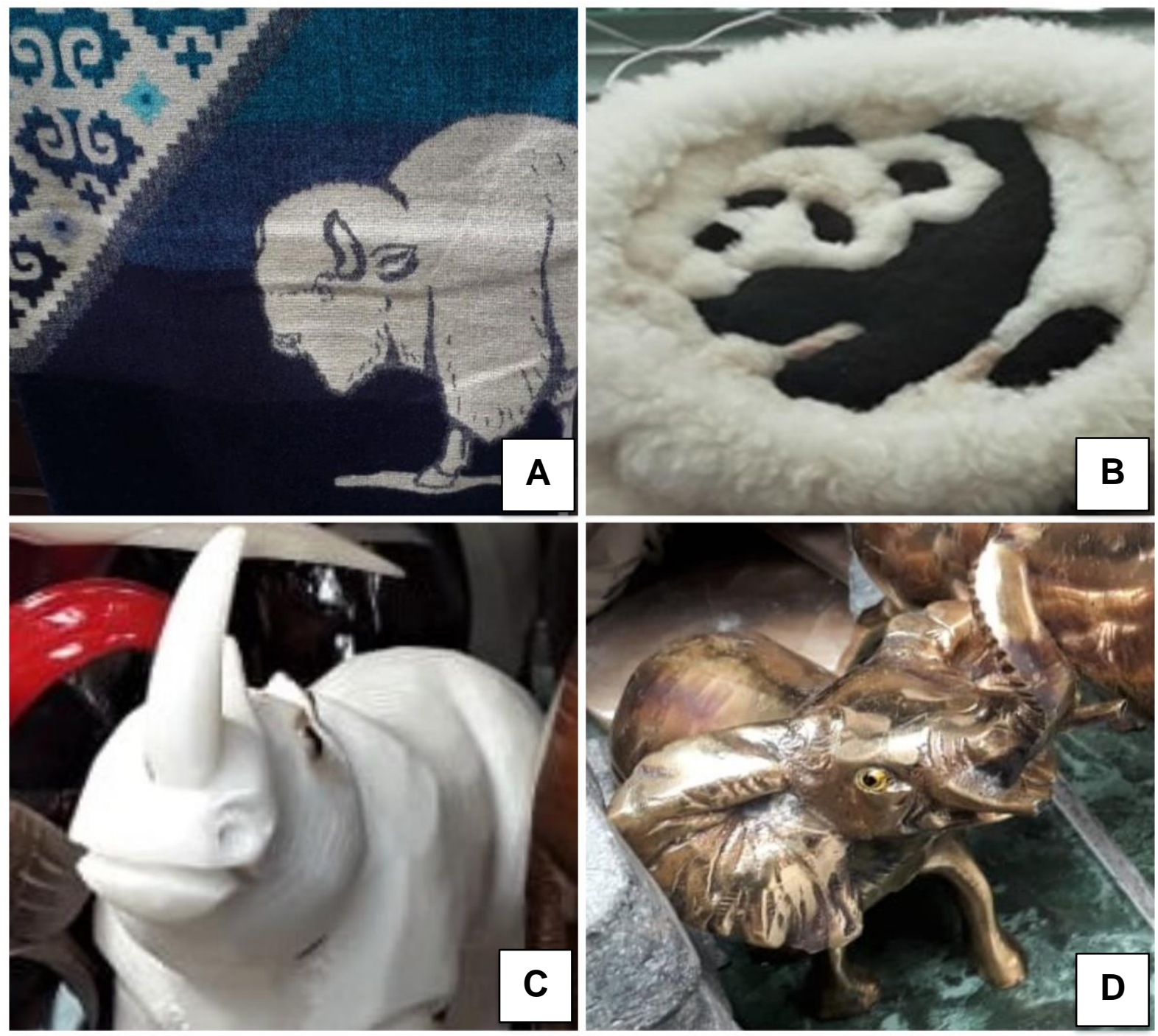

Figura 10: Artesanías decoradas con figuras de animales no representativos del Ecuador: A. Textil con figura de búfalo, B. Textil con figura de oso panda, C. Adorno de tagua con forma de rinoceronte, D. Adorno de cerámica en forma de elefante. Fuente: los autores (2019).

El segundo grupo taxonómico más representado fueron las aves (Figura 11), principalmente especies emblemáticas y endémicas del Ecuador como Vultur gryphus (Linnaeus, 1758) cóndor andino, que se encontró en diferentes artesanías desde cerámica hasta textil. Varias artesanías estaban elaboradas en base a las plumas del Pavo cristatus (Linnaeus, 1758) pavo real y así mismo utilizaban los huevos de codorniz para la elaboración de nacimientos navideños. También se observó varias artesanías representando a aves carismáticas como: Ara sp. (guacamayos), Ramphastos sp. (tucanes), colibríes (Trochilidae), entre otros. Además de algunas aves representativas de las Islas Galápagos como: Sula nebouxii (Milne-Edwards, 1882) piqueros de patas azules y Fregata magnificens (Mathews, 1914) fragatas, que en su mayoría estaban plasmadas en adornos de tagua. 

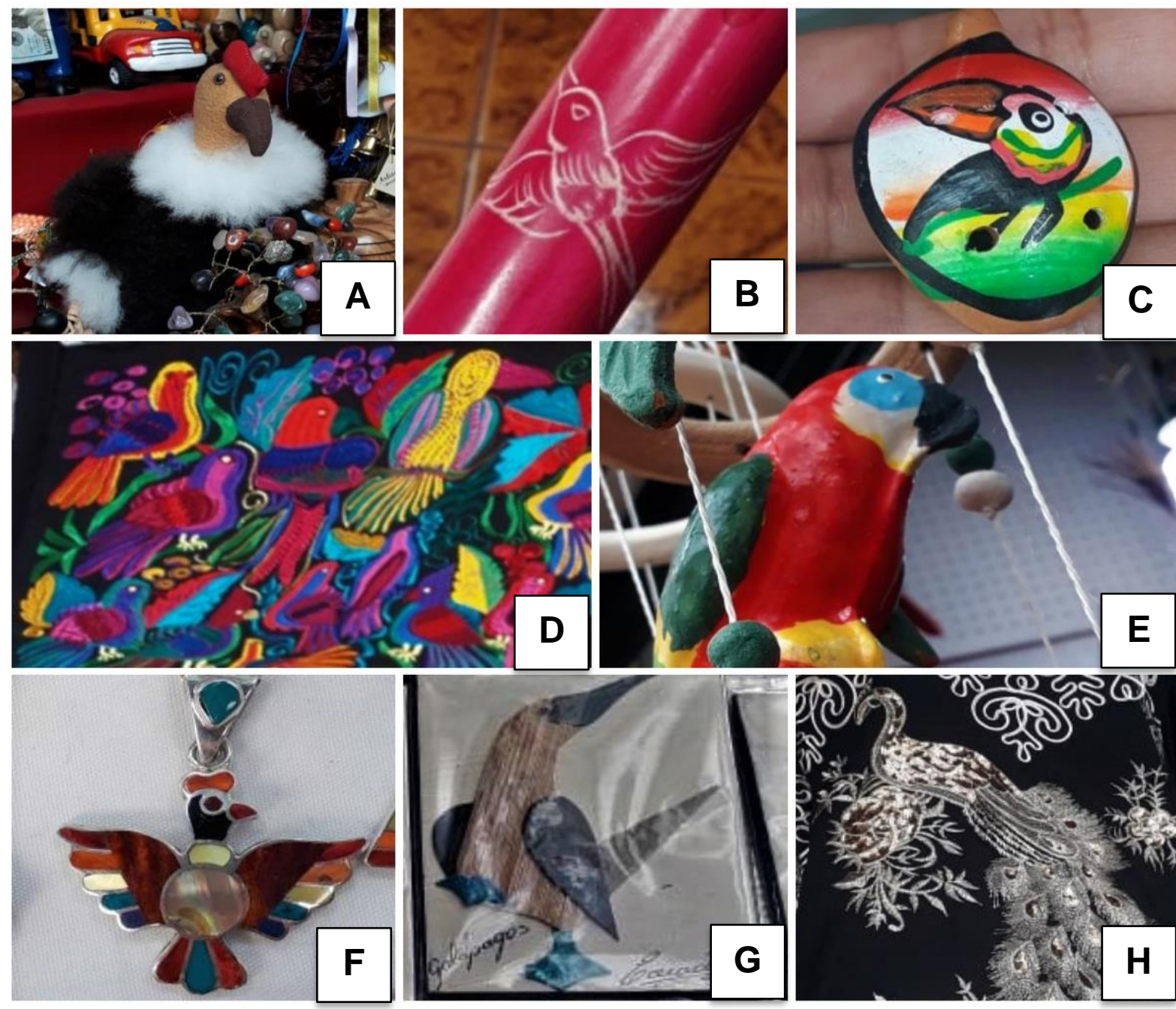

Figura 11: Representación de aves en artesanías: A. Peluche del Cóndor Andino, B. Quena (Instrumento musical) decorado con dibujos de colibríes, C. Imán de madera decorado con dibujo de un tucán, D. Textil bordado con figuras de diferentes aves, E. Adorno de cerámica con forma de guacamayo, F. Dije de plata con representación del Cóndor Andino, G. Pintura en acuarela del piquero de patas azules, H. Pavo real plasmado en una prenda de vestir. Fuente: los autores (2019).

En el grupo de reptiles se identificó varias figuras de caimanes, iguanas, lagartijas, serpientes, tortugas terrestres y marinas, que son parte de la fauna de las cuatro regiones del Ecuador (Figura 12). Se observó varios instrumentos musicales como la quena, zampoña, charango y guasá (sonajero) que estaban adornados con representaciones de reptiles. 

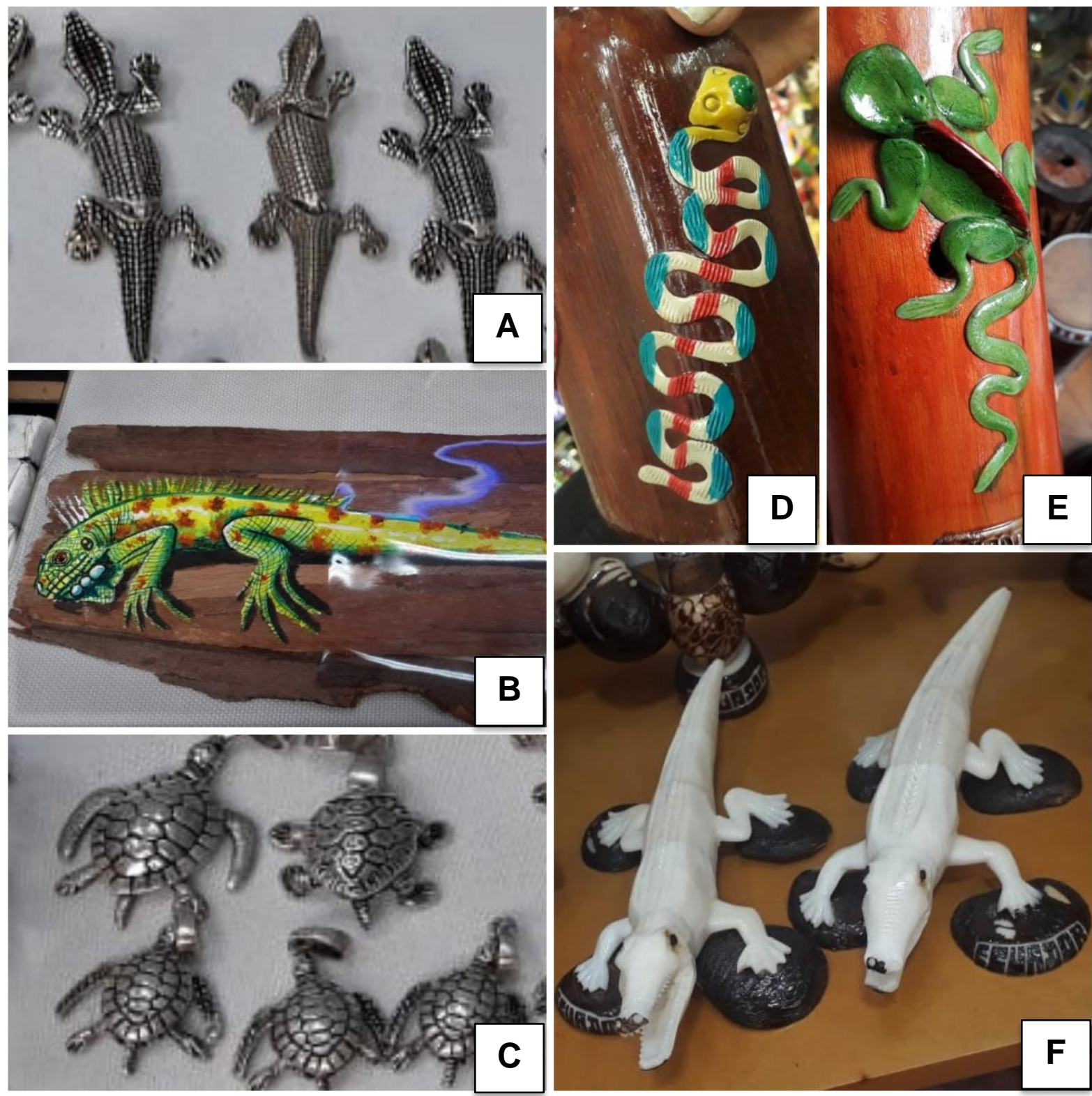

Figura 12: Reptiles representados en diferentes artesanías: A. Dijes de plata con forma de lagartijas, B. Pintura de una iguana sobre una corteza de árbol, C. Dijes de plata con forma de tortugas marinas, D. Botella de madera adornada con una figura de serpiente, E. Guasá decorada con la figura de una iguana, F. Adornos en forma de caimán elaborado en tagua. Fuente: los autores (2019).

Por otro lado, las artesanías fueron decoradas con diferentes tipos de peces presentes en las aguas ecuatorianas. Las mismas que están fabricadas con diversos materiales como mármol, barro, arcilla y más (Figura 13). 

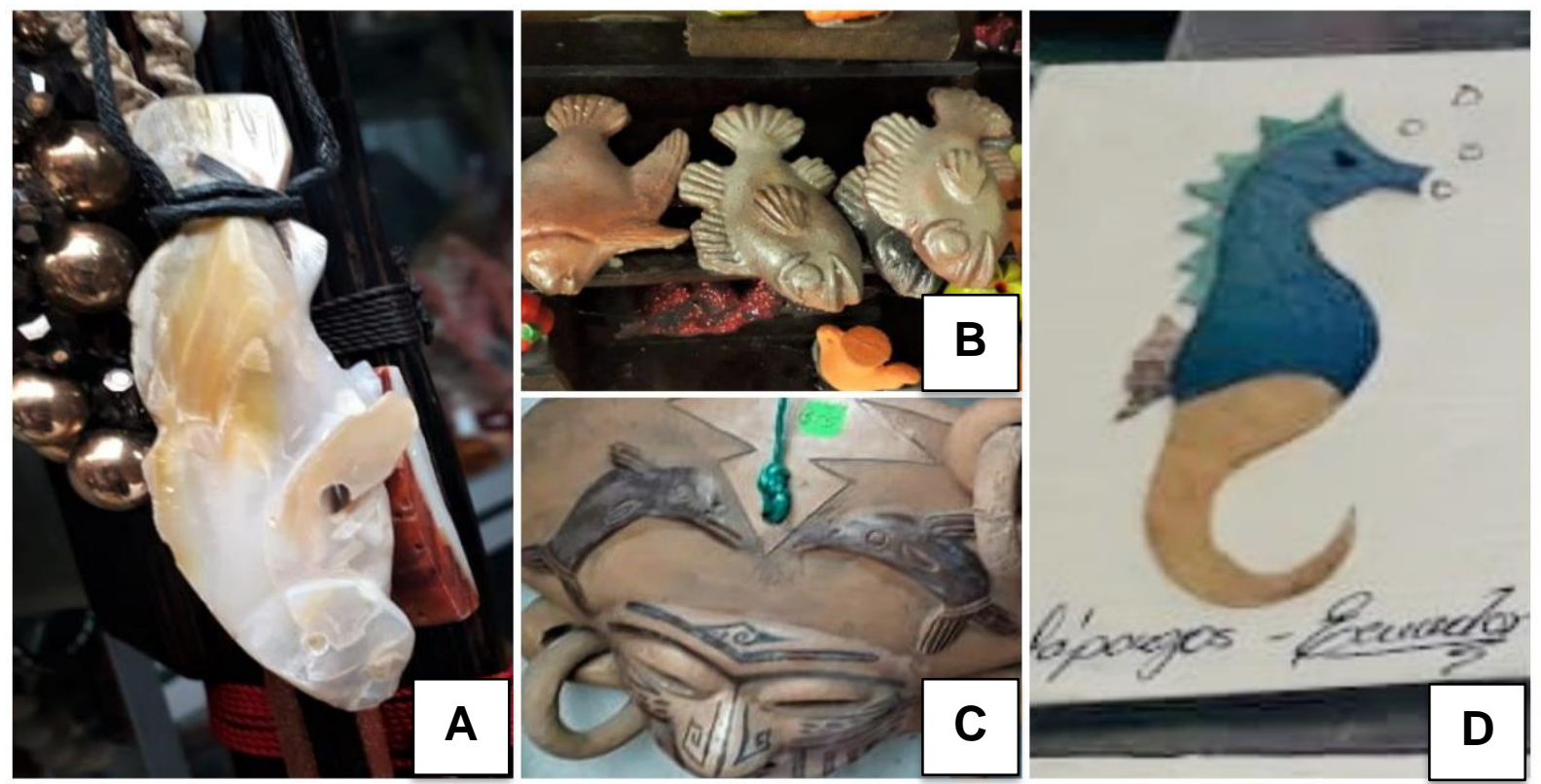

Figura 13: Artesanías con figuras de peces: A. Adorno de pez tallado en mármol, B. Imanes hechos de porcelana, C. Cerámica prehispánica adornada con delfines, D. Pintura en acuarela de un caballito de mar. Fuente: los autores (2019).

A diferencia de los animales vertebrados mencionados anteriormente, los anfibios fueron los animales menos representados en las artesanías (Figura 14). A pesar de que en la cosmovisión andina, las ranas y los sapos tienen diversos significados simbólicos usualmente relacionados con la fertilidad. Además, Ecuador alberga la tercera anfibiofauna más numerosa a nivel mundial con un total de 633 especies (RON; MERINO; ORTIZ, 2020). Desafortunadamente, la riqueza de los anfibios ecuatorianos es casi desconocida para la mayoría de los turistas extranjeros, conforme comentado por otro artesano: "A las personas no les gusta los sapos ni ranas los consideran feos y desagradables" según comento un comerciante.
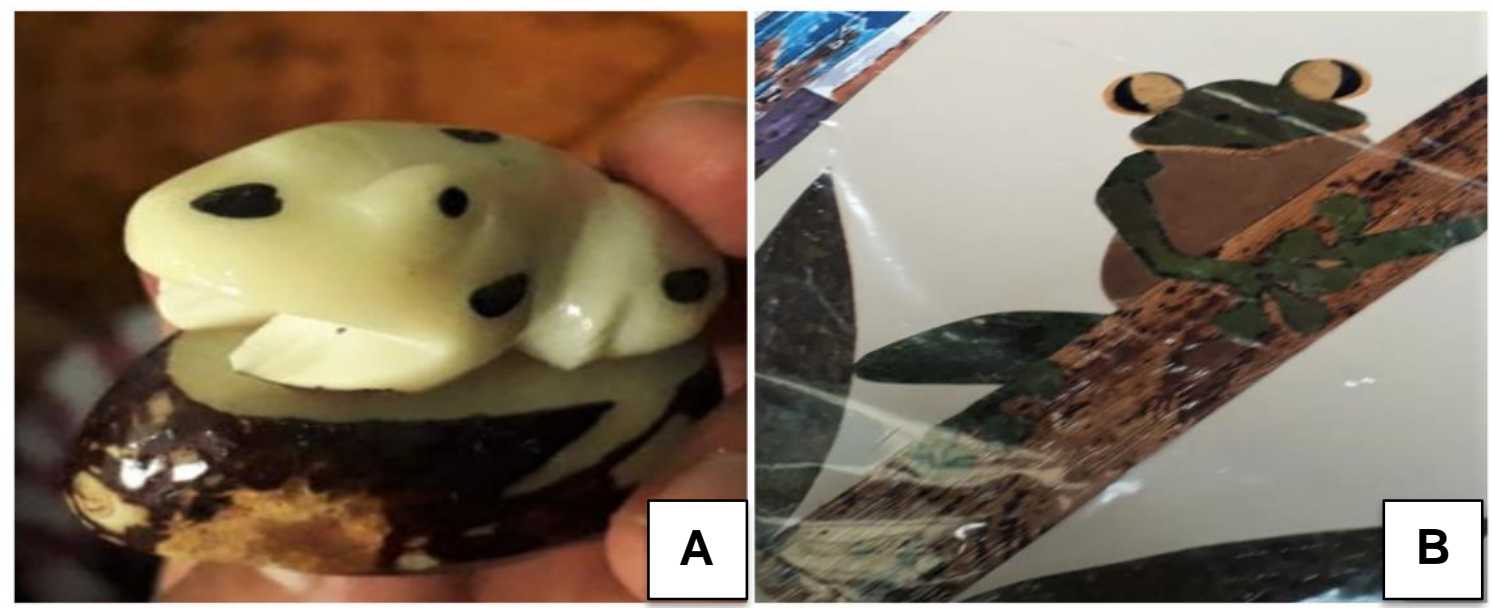

Figura 14: Anfibios representados en artesanías: A. Sapo elaborado en tagua, B. Rana hecha de estructuras vegetales. Fuente: los autores (2019). 
A pesar de la gran diversidad de insectos en el Ecuador, fueron pocas las artesanías de este grupo de invertebrados. Según explicó un artesano, la escasa representatividad de este grupo se debe a que la mayoría de los turistas sienten un rechazo por los insectos. En su habla: "Casi nadie compra artesanías de insectos porque les tienen miedo". Otra de las posibles razones es que, al ser animales de tamaño pequeño o mediano, son poco llamativos para la decoración y el comercio. Se encontró algunos órdenes de insectos como Coleóptera (escarabajos, mariquitas), Lepidóptera (mariposas) y Odonata (libélulas), representadas principalmente en joyería. Este fue el único grupo taxonómico donde se observó artesanías en base a la preservación de animales (Figura 15).
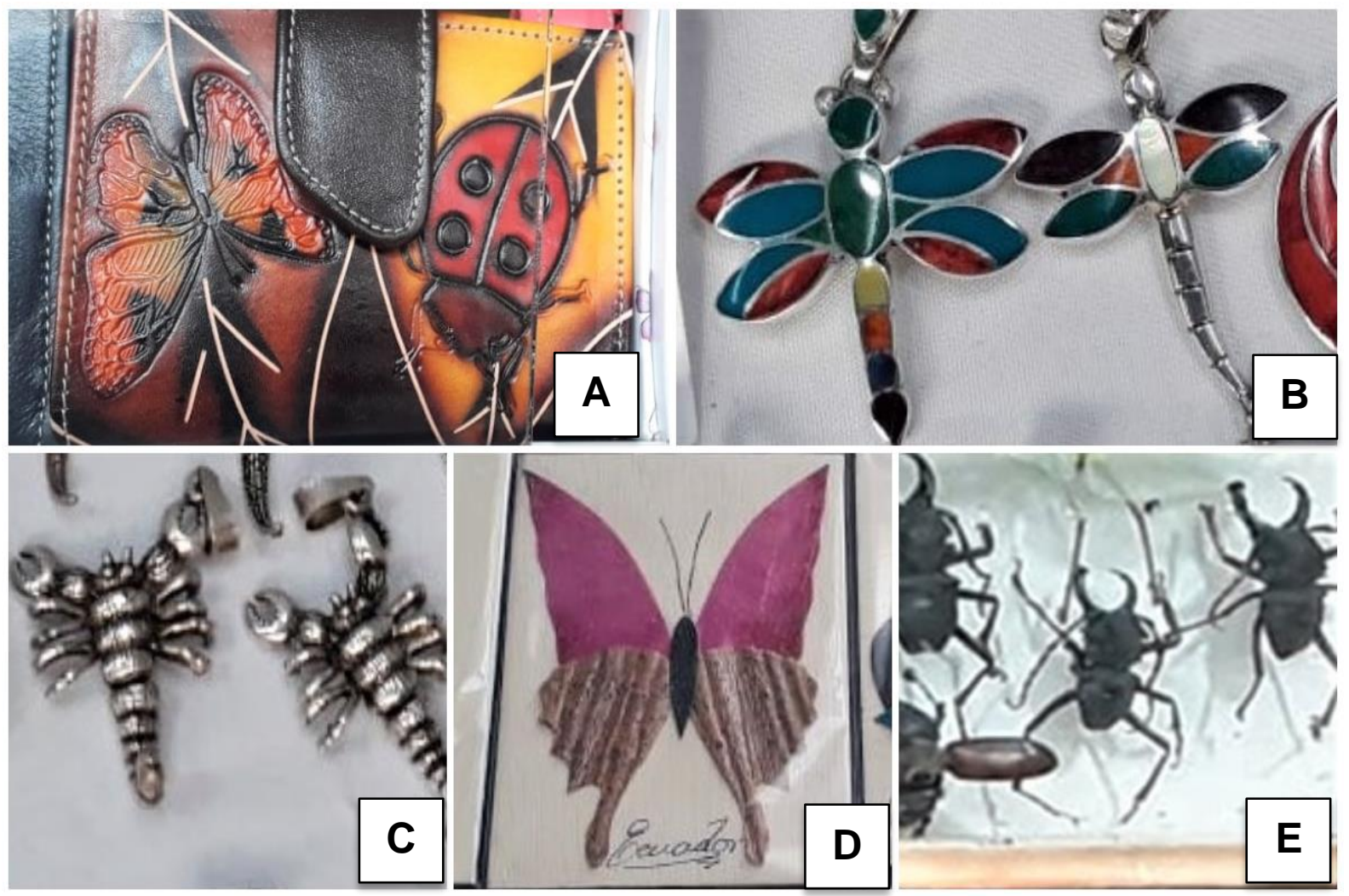

Figura 15: Diferentes insectos representados en artesanías: A. Billetera con imágenes de mariposa y mariquita, B. Dijes de plata con forma de libélulas, C. Dijes con forma de un alacrán, D. Pintura en acuarela de una mariposa, E. Caja entomológica de escarabajos. Fuente: los autores (2019).

Algo observable es que pocos de los artesanos que fueron entrevistados tenían conocimiento acerca del significado ancestral de algunos taxones que están vinculados a su cultura y su comunidad (Tabla 1). Las especies faunísticas que se encuentran relacionadas a la cultura andina son: cóndor andino, lobo de páramo, cuy, llama y conejo andino. Las dos primeras especies son de importancia espiritual y se encuentran amenazadas, mientras que las tres últimas no se encuentran en una categoría de amenaza y fueron domesticadas por las 
comunidades andinas. La llama, por su vez, es un animal de carga, productor de lana y además es una fuente rica en proteína animal. De importancia alimenticia es también la domesticación del cuy y el conejo (GOLTE, 1981).

Tabla 1: Significado ancestral de las representaciones faunísticas en la decoración de las artesanías

\begin{tabular}{lll}
\hline Especies & Significado & Lista Roja del Ecuador \\
\hline Vultur gryphus & Lleva las plegarias a los dioses. & En Peligro \\
\hline Pseudalopex culpaeus & Guía espiritual & Vulnerable \\
\hline Cavia porcellus & Libera malas energías & Preocupación menor \\
\hline Lama glama & Reina de los Andes & Preocupación menor \\
\hline Sylvilagus andinus & Fertilidad & No evaluada
\end{tabular}

Fuente: Tirira (2011); Freile et al. (2019).

En el estudio realizado por Valdés et al. (2001) acerca de la expresión faunística de las figuras de Aguateca-Guatemala, obtuvieron como resultados que los principales animales representados fueron: cánidos, monos, jaguares, y una gran variedad de aves y murciélagos. Algunos de estos animales se relacionaban con sacrificios al cielo, algunos considerados como dioses y patrones de la escritura y en su gran mayoría temas de divinidad. A diferencia de nuestro estudio en donde la mayoría de comerciantes desconocía el significado de las artesanías que estaban ofertando, ya que solo el $20 \%$ de los informantes pudieron indicar el significado ancestral de sus artesanías.

De acuerdo con el concepto desarrollista, los artesanos indígenas deben luchar en un mercado competitivo en el que las artesanías se convierten en un commodity, es decir, un producto de baja calidad que carece de diferenciación por su enfoque de producción masiva. Como consecuencia, las artesanías pierden identidad cultural y dejan de ser parte de su estilo de vida (BENÍTEZ, 2009).

\section{CONCLUSIONES}

El presente estudio evidencia que el Mercado Artesanal "La Mariscal" cuenta con una gran riqueza cultural, llena de artesanías donde la mayoría son el resultado de la cosmovisión indígena inspirada en la fauna presente en las cuatro regiones del Ecuador (Costa, Sierra, 
Amazonía y Galápagos), así también para la elaboración de las mismas utilizan una gran variedad de fibras, maderas, cueros, etc.

La materia prima generalmente es obtenida en la región donde habita el artesano, esto implica que el producto se diferencia de otros, al tener una identidad regional propia. Pero también revela una cultura que va perdiendo su autenticidad ante la superficialidad de un mundo globalizado. Esto se evidencia, en que la iconografía foránea está ganando un espacio cada vez mayor dentro del Mercado, reemplazando así a la artesanía autóctona.

Por fin, cabe puntuar que en la artesanía ecuatoriana es evidente el predominio del trabajo manual sobre el fabril, lo que da a cada pieza un valor único e irreemplazable. Por lo que es importante recuperar las técnicas y diseños propios como estrategia de valor cultural y económico.

\section{AGRADECIMIENTOS}

Agradecemos a los comerciantes entrevistados en el mercado artesanal "La Mariscal" por su colaboración y tiempo al momento de realizar las entrevistas. Finalmente, a nuestro docente Iván Jácome por su apoyo en el desarrollo del presente estudio.

\section{REFERENCIAS BIBLIOGRÁFICAS}

ARGUETA, V. A. et al. Historia, situación actual y perspectivas de la Etnozoología en México. Etnobiología, México, v. 10, n.1, p. 19-40, 2012. Disponible en: https://www.revistaetnobiologia.mx/index.php/etno/article/view/114. Acceso en: 23 ago. 2020.

BENÍTEZ, S. Dinámica de la artesanía latinoamericana como factor de desarrollo económico, social y cultural. Revista cultural y Desarrollo. p. 3-10, 2009.

BUENAÑO, A. M. et al. Los Kichwas Otavalos su artesanía y el turismo. Revista Publicando, Otavalo, v. 3, n.7, p. 346-353, 2016. Disponible en: https://dialnet.unirioja.es/servlet/articulo?codigo=5833454. Acceso: 23 ago. 2020.

ECUADOR. Instituto Nacional de Patrimonio Cultural. Estudio etnoarqueológico de técnicas ancestrales de producción cerámica y diseños de referentes identitarios en la provincia de Tungurahua, cantón Patate, parroquia sucre, para su aplicación y valorización. Quito- Ecuador. Sacharxeos, 2014. 111 p.

ECUADOR. Ministerio de Turismo. Mercado Artesanal "La Mariscal", un referente turístico en Quito, está de aniversario. Quito, 2017. Disponible en: https://www.turismo.gob.ec/mercado-artesanal-la-mariscal-un-referente-turistico-en-quitoesta-de-aniversario/. Acceso: 11 de oct. 2017. 
FERRO, D. Identidad, cultura e innovación en las artesanías: un camino para el desarrollo sustentable y el Buen Vivir. Estudios de la Gestión: Revista Internacional de Administración. n.1, p. 95-116. 2015. Disponible en: http://repositorio.uasb.edu.ec/handle/10644/5477. Acceso: 23 ago. 2020.

FREILE, J. F. et al. Lista roja de las aves del Ecuador. Quito: Ministerio del Ambiente, Aves y Conservación, Comité Ecuatoriano de Registros Ornitológicos, Fundación Charles Darwin, Universidad del Azuay, Red Aves Ecuador y Universidad San Francisco de Quito, 2019. $51 \mathrm{p}$.

GOLTE, J. Cultura y naturaleza andinas. Revista Allpanchis, Lima, v. 15, n. 17/18, p. 119$132,1981$.

GUAPISACA, L. La semiótica de los pictogramas de la cultura Salasaca y su influencia en el trabajo de sus artesanos. 2019. 128 p. Tesis (Ingeniería en Diseño Gráfico Publicitario), Universidad Técnica de Ambato, Ambato.

LARRAÍN, H. Demografía y asentamientos indígenas en la sierra norte del Ecuador en el siglo XVI: estudio etnohistórico de las fuentes tempranas. Quito: Banco Central del Ecuador: Instituto Otavaleño de Antropología, 1980. 221 p.

LÓPEZ, H. Mapa de Parroquias de Quito. Disponible en: https://es.wikipedia.org/wiki/Archivo:Mapa_de_Parroquias_de_Quito.jpg. Acceso: 04 Nov. 20 de 2020. 2009.

RIVERA, C. M. et al. La artesanía como producción cultural susceptible de ser atractivo turístico en Santa Catarina del Monte, Texcoco. Convergencia, v.15, n.46. p. 225-247. 2008. Disponible en: http://www.scielo.org.mx/scielo.php?script=sci_arttext\&pid=S140514352008000100010. Acceso: 23 ago. 2020.

RON, S.; MERINO, V. A.; ORTIZ, D. Anfibios del Ecuador. Museo de Zoología, Pontificia Universidad Católica del Ecuador. PECE, 2020. Disponible en: https://bioweb.bio/faunaweb/amphibiaweb/. Acceso: 21 ago. 2020.

SARANGO, A. Construcción y Consolidación de un Modelo De Gestión Forestal para el Distrito Metropolitano De Quito. Secretaría de Ambiente, Sacharxeos, Quito, p. 95, 2013.

SARASTY, M. Levantamiento cartográfico de $\mathbf{4}$ grupos de música andina y folclórica de la zona urbana del municipio de Pasto Nariño. 2015. 61 p. Tesis (Licenciado en Música)- Facultad de Artes. Universidad de Nariño. San Juan de Pasto-Colombia.

TIRIRA, D. Lista Roja de mamíferos del Ecuador. 2. ed. Quito: Fundación Ecociencia, 2011, 398 p.

VALDÉS, J. et al. Lo que expresan las figurillas de Aguateca acerca del hombre y los animales. En: XIV Simposio de Investigaciones Arqueológicas en Guatemala. 2001, Guatemala. Lo que expresan las figurillas de Aguateca acerca del hombre y los animales. Guatemala: Museo Nacional de Arqueología y Etnología, 2001, p. 654-676. 